Supporting information

\title{
One-Step DNA-Programmed and Flash Synthesis of Anisotropic Noble Metal Nanostructure on MXene
}

Menglin Song, Yongxin Lyu, Feng Guo, Sin-Yi Pang, Man-Chung Wong, Jianhua Hao*

Department of Applied Physics, The Hong Kong Polytechnic University, Hong Kong, 999077, P. R.

China

*Corresponding author. E-mail: jh.hao@polyu.edu.hk 


\section{Chemicals and Materials}

Multilayer $\mathrm{Ti}_{3} \mathrm{C}_{2}$ MXene was purchased from Laizhou Kai Ceramic material Co., Ltd. Tetramethylammonium hydroxide (TMAOH), hydrogen tetrachloroaurate (III) hydrate $\left(\mathrm{HAuCl}_{4} \cdot 3 \mathrm{H}_{2} \mathrm{O}, 99.999 \%\right)$ palladium (II) chloride ( $\left.>99.9 \%\right)$, and platinum (IV) chloride ( $\left.>99.9 \%\right)$ were obtained from Sigma-Aldrich. The metal precursors $\left(\mathrm{PdCl}_{2}, \mathrm{PtCl}_{4}\right)$ are dissociated by hydrochloric acid to create metal anions, $\left[\mathrm{PdCl}_{4}\right]^{2-},\left[\mathrm{PdCl}_{6}\right]^{4-}$. Preparation process of precursors solution: $0.02 \mathrm{M}$ diluted solutions of $\mathrm{HCl}$ were introduced into $0.04 \mathrm{M} \mathrm{H}_{2} \mathrm{PdCl}_{4} / \mathrm{H}_{2} \mathrm{PtCl}_{6}$ solution in a water bath with stirring. All these chemicals were used as received without further purification.

$$
\begin{gathered}
\mathrm{PdCl}_{2}+2 \mathrm{HCl} \rightarrow \mathrm{H}_{2} \mathrm{PdCl}_{4} \\
\mathrm{PtCl}_{4}+2 \mathrm{HCl} \rightarrow \mathrm{H}_{2} \mathrm{PtCl}_{6}
\end{gathered}
$$

\section{Oligonucleotides}

All Oligonucleotides used in this study were purchased from Integrated DNA Technologies Inc.

Table S1. Oligonucleotides were used in this study.

\begin{tabular}{|c|c|}
\hline DNA Sequences & Sequence (5'-3') \\
\hline A30 & AAAAAAAAAA AAAAAAAAAAAAAAAAAAAA \\
\hline C30 & CCCCCCCCCC CCCCCCCCCC CCCCCCCCCC \\
\hline T30 & TTTTTTTTTTTTTTTTTTTTTTTTTTTTTT \\
\hline R25 & CGGCCTCAAACTGAGTATTCAT \\
\hline FAM-A30 & FAM-AAAAAAAAAA AAAAAAAAAAAAAAAAAAAA \\
\hline
\end{tabular}




\section{Preparation of few-layers $\mathrm{Ti}_{3} \mathrm{C}_{2} \mathrm{~T}_{\mathrm{x}} \mathrm{MXene}$ flake suspension}

Typically, $\mathrm{Ti}_{3} \mathrm{C}_{2} \mathrm{~T}_{\mathrm{x}}$ MXene was synthesized by selective etching from the $\mathrm{Ti}_{3} \mathrm{AlC}_{2}$ at room temperature with $5 \mathrm{M} \mathrm{LiF} / 6 \mathrm{M} \mathrm{HCl}$ solution for 24 hours. After the etching is finished (complete removal of $\mathrm{Al}$ element layers), it is necessary to wash the product for removing the residual acid and salts and repeat the step for three time. When the $\mathrm{pH}$ of the solution is up to 6 , the multi-layered $\mathrm{Ti}_{3} \mathrm{C}_{2} \mathrm{~T}_{\mathrm{x}} \mathrm{MXene}$ can be collected. For the delamination step, we used TMAOH as intercalant. $12 \mathrm{~mL} \mathrm{25 \%} \mathrm{TMAOH}$ was reacted with multi-layered MXene $(20 \mathrm{mg})$ for $24 \mathrm{~h}$. When the reaction finished, the suspension was washed and collected by centrifugation to obtain TMA-intercalated $\mathrm{Ti}_{3} \mathrm{C}_{2} \mathrm{~T}_{\mathrm{x}}$. The sediment was dispersed in $2 \mathrm{~mL}$ distilled water, and the multi-layered-MXene was further delaminated for $10 \mathrm{~min}$ by sonication, and then the solution was centrifuged to collect the few-layered $\mathrm{Ti}_{3} \mathrm{C}_{2} \mathrm{~T}_{\mathrm{x}}$. To alleviate its oxidation, the obtained MXene was dried in vacuum.

\section{One-step synthesis of Au nanospheres on MXene}

$0.5 \mathrm{~mL}$ few-layered $\mathrm{Ti}_{3} \mathrm{C}_{2} \mathrm{~T}_{\mathrm{x}}$ MXene $(200 \mu \mathrm{g} / \mathrm{mL})$ suspension react with $\mathrm{HAuCl}_{4}$ aqueous solution $(20$ $\mathrm{mL}, 25 \mathrm{mM}$ ) with different concentrations for 10 minutes at room temperature. After the reaction finished, the color of the solution turns dark red. The product was collected by centrifugation at 10000 rpm for $10 \mathrm{~min}$ and resuspended in D.I. water and repeat this step for three times. The reaction between Au precursor and MXene is shown as follows:

$$
3 \mathrm{Ti}_{3} \mathrm{C}_{2} \mathrm{O}_{\mathrm{x}}(\mathrm{OH})_{\mathrm{y}} \mathrm{F}_{\mathrm{z}}+\beta \mathrm{HAuCl}_{4} \rightarrow 3 \mathrm{Ti}_{3} \mathrm{C}_{2} \mathrm{O}_{\mathrm{x}+\beta}(\mathrm{OH})_{\mathrm{y}-\beta} \mathrm{F}_{\mathrm{z}}+\beta \mathrm{Au}+4 \beta \mathrm{HCl}
$$

In order to mediate the morphology of Au nanostructures on MXene, ssDNA was used as the caping agent and regulator. MXene served as an excellent subtract and mild reductant. It is known that the 
binding affinity between poly DNA and the gold is in the order of Poly A $>$ Poly $\mathrm{C}>$ Poly $\mathrm{T}$. Subsequently, we then evaluated the role of different ssDNA sequences in tuning the morphology of Au nanostructure.

To synthesize $\mathrm{Au}$ nanourchins on MXene, $0.5 \mathrm{~mL}$ few-layered $\mathrm{Ti}_{3} \mathrm{C}_{2} \mathrm{~T}_{\mathrm{x}}$ MXene $(200 \mu \mathrm{g} / \mathrm{mL})$ suspension reacted with $3 \mu \mathrm{M}$ Poly A30 (Au nanoflowers: $1 \mu \mathrm{M}$ Poly A30; Au nanoflowers: 1 or 3 $\mu \mathrm{M}$ Poly C30; diamond-like Au nanostructures: $1 \mu \mathrm{M}$ Poly T30; petal-like Au nanostructures: $1 \mu \mathrm{M}$ Poly T30) solution for 10 minutes stirring at room temperature. After the adsorbed DNA on MXene is saturated, the gold precursor $(20 \mathrm{~mL}, 25 \mathrm{mM})$ was added into the solution, and keep stirring for $5 \mathrm{~min}$. The dark red solution will be obtained, and the product was collected by centrifugation at $10000 \mathrm{rpm}$ for $10 \mathrm{~min}$ and resuspended in D.I. water and repeat this step for three times.

\section{DNA-tailored synthesis of other anisotropic noble metal nanostructure on MXene}

Firstly, $0.5 \mathrm{~mL}$ MXene $(200 \mu \mathrm{g} / \mathrm{mL})$ suspension was vortexed with $3 \mu \mathrm{M}$ poly A30 or C30 or T30 for $10 \mathrm{~min}$, and then $20 \mu \mathrm{L} \mathrm{H}_{2} \mathrm{PdCl}_{4}$ or $\mathrm{H}_{2} \mathrm{PtCl}_{6}(25 \mathrm{mM}$ )( solution was added into the mixture to initiate the reduction and anisotropic growth at room temperature for 5 minutes. The mixture turns to be dark blue after the reaction. The as-prepared nanocomposites were obtained by centrifugation at $10000 \mathrm{rpm}$ and washed three times with D.I. water.

$$
\begin{aligned}
& 3 \mathrm{Ti}_{3} \mathrm{C}_{2} \mathrm{O}_{\mathrm{x}}(\mathrm{OH})_{\mathrm{y}} \mathrm{F}_{\mathrm{z}}+\beta \mathrm{H}_{2} \mathrm{PdCl}_{4} \rightarrow 3 \mathrm{Ti}_{3} \mathrm{C}_{2} \mathrm{O}_{\mathrm{x}+\beta}(\mathrm{OH})_{\mathrm{y}-\frac{2}{3} \beta} \mathrm{F}_{\mathrm{z}}+\beta \mathrm{Pd}+4 \beta \mathrm{HCl} \\
& 3 \mathrm{Ti}_{3} \mathrm{C}_{2} \mathrm{O}_{\mathrm{x}}(\mathrm{OH})_{\mathrm{y}} \mathrm{F}_{\mathrm{z}}+\beta \mathrm{H}_{2} \mathrm{PtCl}_{6} \rightarrow 3 \mathrm{Ti}_{3} \mathrm{C}_{2} \mathrm{O}_{\mathrm{x}+\beta}(\mathrm{OH})_{\mathrm{y}-\frac{4 \beta}{3} \mathrm{~F}_{\mathrm{z}}+\beta \mathrm{Pt}+6 \beta \mathrm{HCl}}
\end{aligned}
$$

\section{Evaluation of binding affinity between FAM-A30 and $\mathrm{Ti}_{3} \mathrm{C}_{2}$ MXene}


ssDNA FAM-A30 $\left(15 \mu \mathrm{L}, 1.0 \times 10^{-5} \mathrm{M}\right)$ was added into MXene suspension $(200 \mu \mathrm{g} / \mathrm{mL}, 500 \mu \mathrm{L})$ solution. After brief mixing, $\mathrm{HAuCl}_{4}$ solution $(20 \mu \mathrm{L}, 25 \mathrm{~m} \mathrm{M})$ was added to the solution. Then the mixture was centrifuged at $10000 \mathrm{rpm}$. The samples of FAM-A30 $\left(15 \mu \mathrm{L}, 1.0 \times 10^{-5} \mathrm{M}\right)$ dispersed in $520 \mu \mathrm{L}$ D.I water was served as the control. The fluorescence of the supernatant was recorded by using FLS920P Edinburgh Analytical Instrument apparatus.

\section{SERS measurement}

For SERS enhancement ability of MXene -Au nanoflower was measured on a Witec Confocal Raman system. Methylene blue solution $\left(1.0 \times 10^{-5} \mathrm{M}, 20 \mu \mathrm{L}\right)$ was mixed with MXene, MXene-Au nanospheres and MXene-Au_A30 NF $\left(200 \mu \mathrm{g} \mathrm{mL}{ }^{-1}, 20 \mu \mathrm{L}\right)$ and adsorbed onto the surface of nanoparticles. Raman spectra were recorded using the following conditions: laser: $633 \mathrm{~nm}$, power density: $0.4 \mathrm{~mW}$, and acquisition time: $30 \mathrm{~s}$.

\section{Photothermal effect measurement}

$1 \mathrm{~mL}$ aqueous samples (MXene, MXene-Au nanospheres and MXene-Au_A30 NF, $200 \mu \mathrm{g} / \mathrm{mL}$ ) were irradiated with an NIR laser $\left(808 \mathrm{~nm}, 1 \mathrm{~W} \cdot \mathrm{cm}^{-2}\right)$ for $10 \mathrm{~min}$. The temperatures of the solutions were monitored using a digital thermometer, which was submerged in the solution.

\section{Computational methods}

The structure optimization was performed using DFT as implemented in Quantum Espresso. ${ }^{1,2}$ The generalized gradient approximation (GGA) of revised Perdew, Burke and Ernzerhof functional for solids (PBEsol) was employed. Pseudopotentials were obtained from the solid-state pseudopotential 
(SSSP) efficiency library along with their suggested optimal wavefunction kinetic energy cutoffs $\left(\mathrm{E}_{\mathrm{c}}\right){ }^{3}$ According to the SSSP efficiency library, a mix of the three major approaches of pseudization for the constituent elements are employed, including projector-augmented wave (PAW) for $\mathrm{C}, \mathrm{O}$, ultrasoft pseudopotential (USPP) for F, Ti, H, Pt, and norm-conserving (NC) for Au, Pd. Monkhorst-Pack kpoint grid of $13 \times 13 \times 1$ was used to sample the Brillouin zone. A vacuum space of $20 \AA$ was imposed in the perpendicular direction to avoid interactions between periodic images. The convergence threshold on total energy and total force for geometry relaxation were $10^{-5} \mathrm{eV}$ and $0.01 \mathrm{eV} / \AA$, respectively.

The interaction between metal and $\mathrm{Ti}_{3} \mathrm{C}_{2} \mathrm{~T}_{\mathrm{x}}$ monolayers was described by its binding energy:

$$
E_{\text {binding }}=E_{\text {Ti } 3 C 2 T x}-\text { metal }-\left(E_{\text {Ti } 3 C 2 T x}+E_{\text {metal }}\right)
$$

where $E_{\mathrm{Ti} 3 \mathrm{C} 2 \mathrm{Tx}-m e t a l}$ is the total energy of the metal atoms adsorbed on MXene monolayer, $E_{\mathrm{Ti} 3 \mathrm{C} 2 \mathrm{Tx}}$ is the energy of bare $\mathrm{Ti}_{3} \mathrm{C}_{2} \mathrm{~T}_{\mathrm{x}}$, and $E_{\text {metal }}$ is the energy of an isolated metal layer. The structure of $\mathrm{Ti}_{3} \mathrm{C}_{2} \mathrm{~T}_{\mathrm{x}}$ were obtained from open-access crystallography database. ${ }^{4}$ The metal layer of (111) surface was modeled since it is the lowest surface energy plane in fcc metals. The bottom MXene layer and the top metal layer was stacked according to the close-packing arrangement.

\section{Characterization}

Powder X-ray diffraction (XRD) patterns of the as-prepared MXenes and DNA-mediated MXene-NM structures were recorded using a Rigaku smart lab $9 \mathrm{~kW}$ (Rigaku, Japan) with $\mathrm{Cu} \mathrm{K} \alpha$ radiation $(\lambda=$ $1.5406 \AA$ ). The shape, size, and structure of the as-prepared MXene-NM hydrides were characterized by using JEOL-2100F transmission electron microscopy (TEM) equipped with an Oxford Instrument energy dispersive X-ray (EDX) spectrometry system, operating at $200 \mathrm{kV}$. The crystal structure of the 
MXene-NM nanostructures was characterized by selected area electron diffraction (SAED). Samples for TEM were prepared on holey carbon coated 230 mesh copper grids. $\zeta$-Potential measurements were performed on a Zetasizer Zeta Potential Analyzer (Malvern Instruments Ltd., England), and the $\zeta$ potential values were averaged. X-ray photoelectron spectroscopy (XPS) was conducted on Thermo Scientific $^{\mathrm{TM}}$ Nexsa $^{\mathrm{TM}}$ X-Ray photoelectron spectrometer system, coupled to monochromatic and microfocus A1 Ka X-ray source (1486.2 eV). Fluorescence intensity was measured by using FLS920P Edinburgh Analytical Instrument apparatus equipped with an excitation source of Xenon lamp. Raman spectra of the samples were obtained from a Witec Confocal Raman system, paired with an excitation source of continuous wave (C.W.) $633 \mathrm{~nm}$ diode laser of $0.4 \mathrm{~mW}$ laser power.

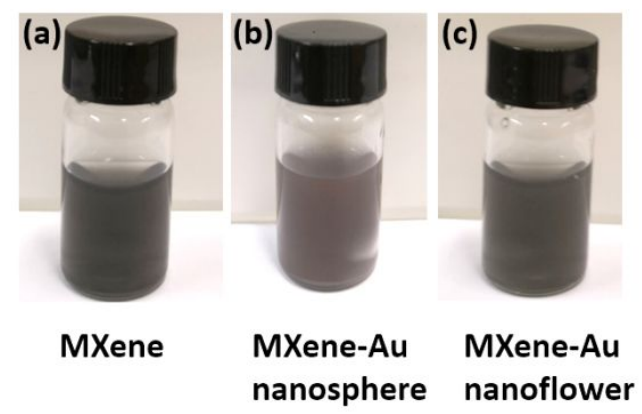

Figure S1. The photography of the (a) MXene nanosheets (b) MXene/Au nanosphere (c) MXene/Au nanoflower dispersion. 

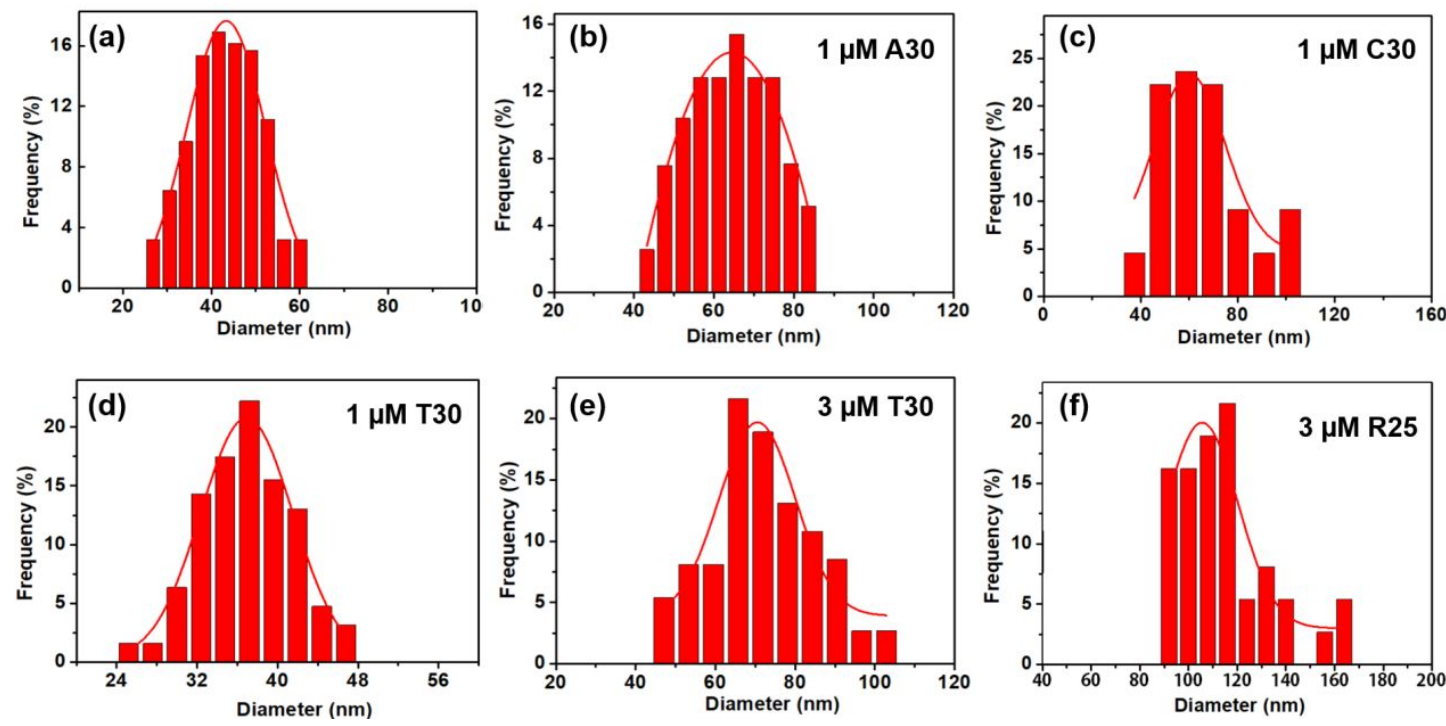

Figure S2. Particle size distribution of gold nanostructure mediated by different nucleotides sequences.
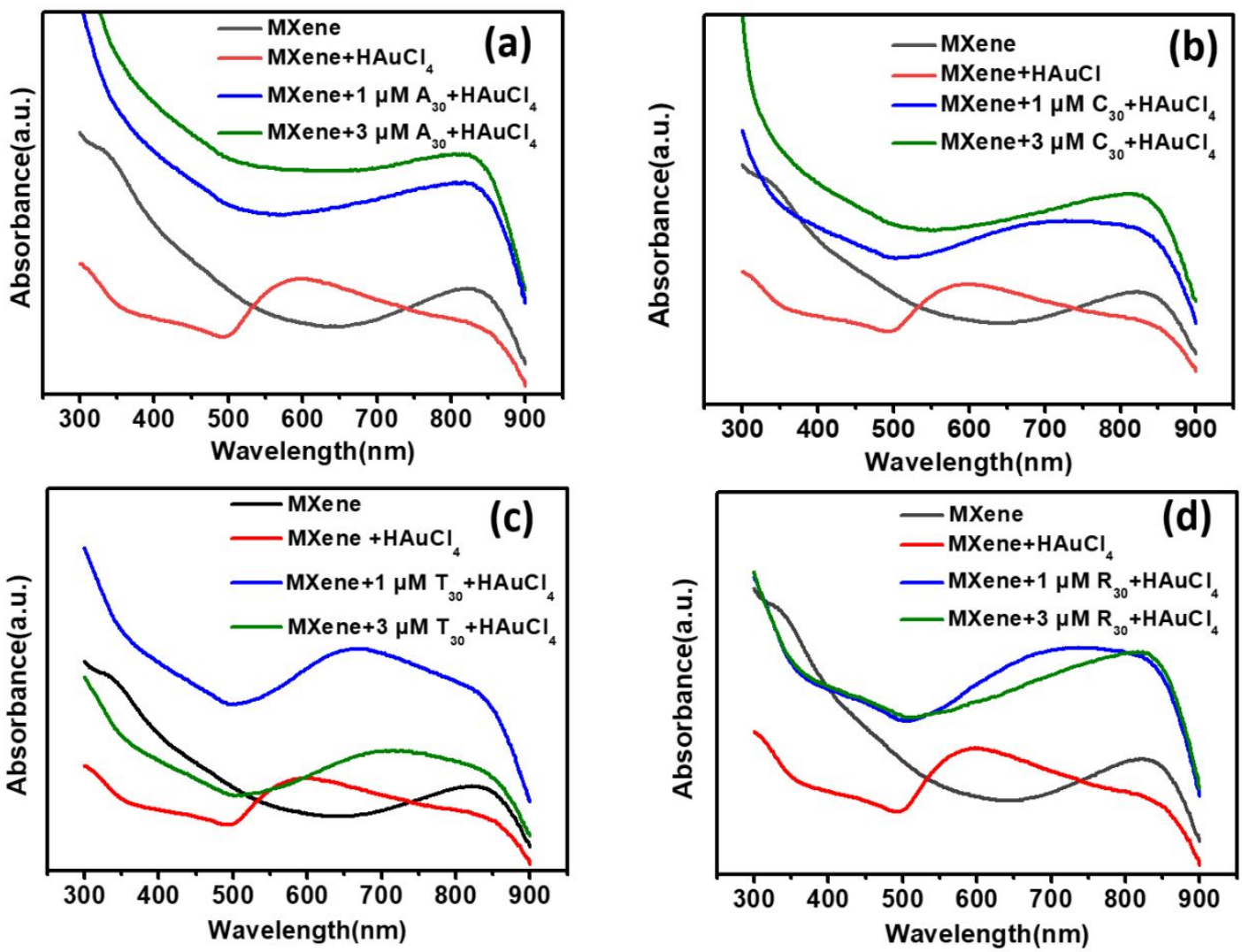

Figure S3. The UV-vis absorption measurement of MXene incubated with different types of oligonucleotides and $\mathrm{HAuCl}_{4}$. MXene $(0.2 \mathrm{mg} / \mathrm{mL})$, MXene incubated with $25 \mu \mathrm{L} \mathrm{HAuCl}{ }_{4}(25 \mathrm{mM}$, 
MXene incubated with $1 \mu \mathrm{M}$ or $3 \mu \mathrm{M}$ (a) A30 oligonucleotides (b) C30 (c) T30 (d) R30 and $25 \mu \mathrm{L}$ $\mathrm{HAuCl}_{4}(25 \mathrm{mM})$.
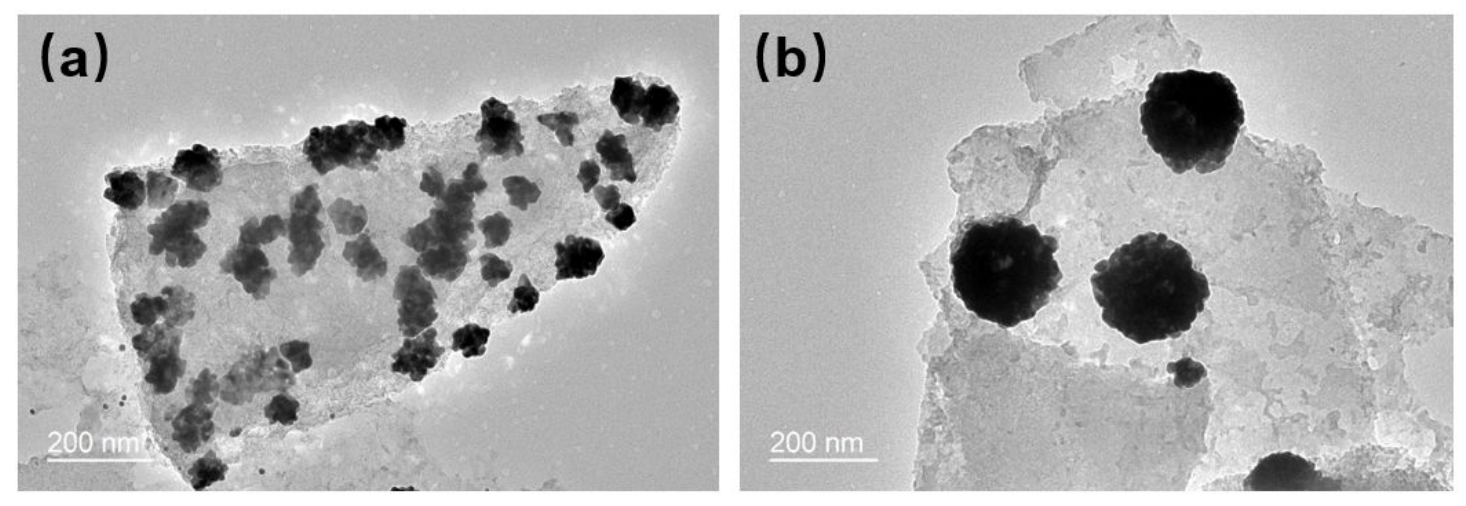

Figure S4. Representative TEM images, showing the dependence of the size and anisotropy of Au nanostructure on the concentration of (a) $1 \mu \mathrm{M} \mathrm{C} 30$ and $1 \mu \mathrm{M}$ random 25 -nucleotide (nt) strands.

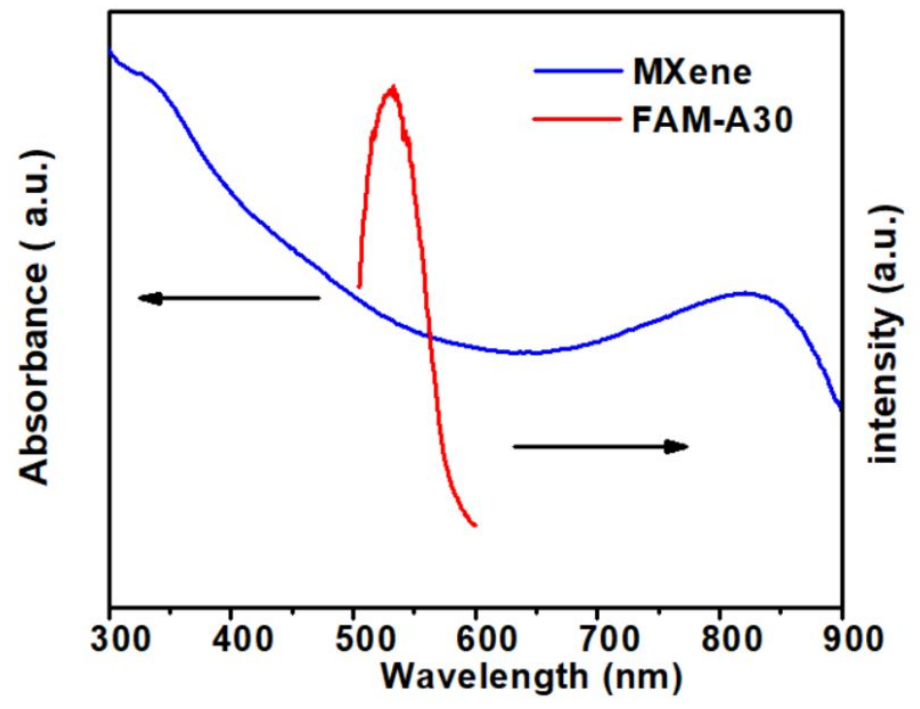

Figure S5. Emission spectra of FAM-A30 excited at $490 \mathrm{~nm}$ and UV-vis absorption spectra of MXene. 


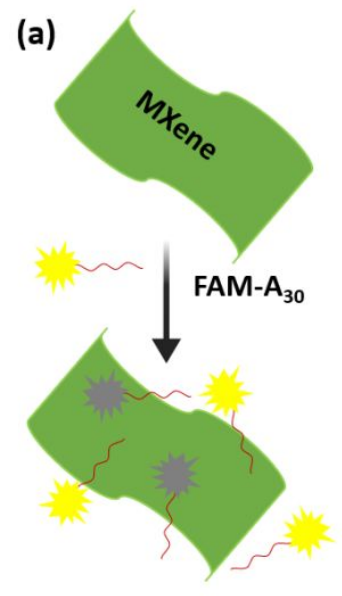

Partially quenched (b)

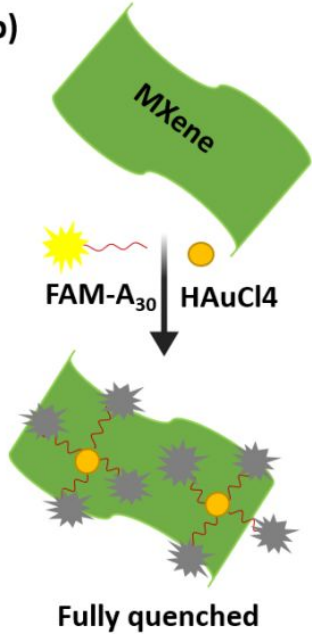

Figure S6. Scheme of adsorption of (a) FAM-labeled A30 on the $\mathrm{Ti}_{3} \mathrm{C}_{2} \mathrm{~T}_{\mathrm{x}}$ MXene with partially quenched fluorescence and (b) FAM-A30 were fully absorbed on MXene with no fluorescence induced by the addition of $\mathrm{AuCl}_{4}$ -

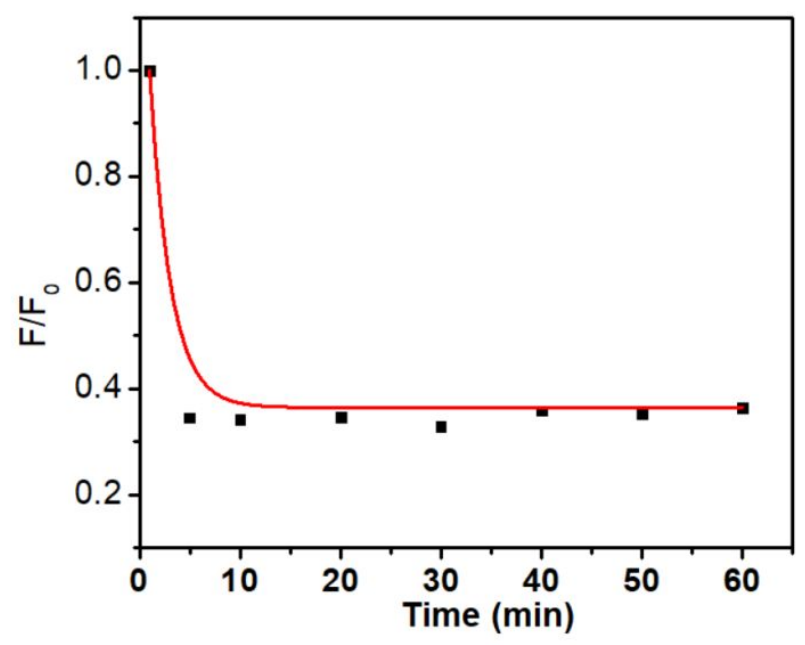

Figure S7. Real-time fluorescence kinetics $\left(\lambda_{\mathrm{ex}}=490 \mathrm{~nm} ; \lambda_{\mathrm{em}}=520 \mathrm{~nm}\right)$. 
(a)

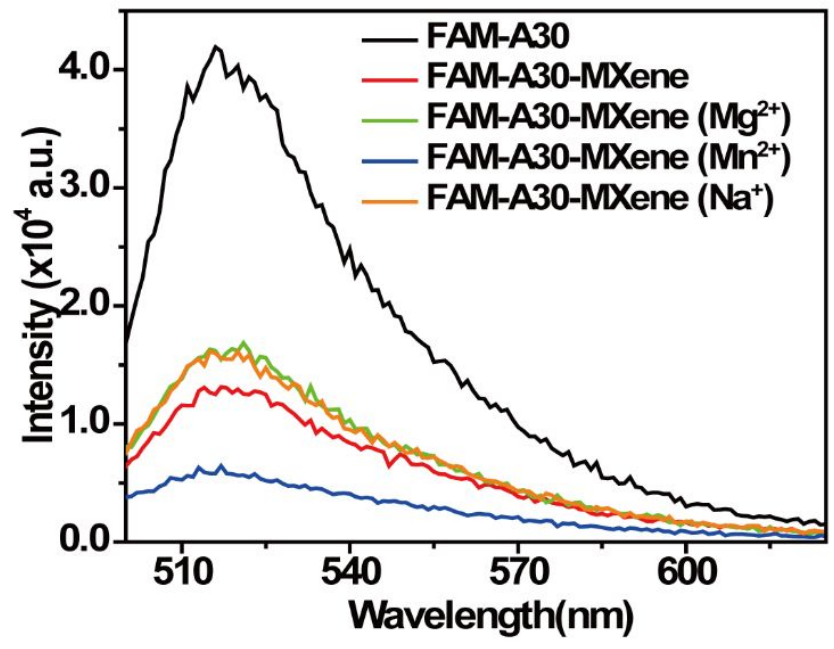

(b)

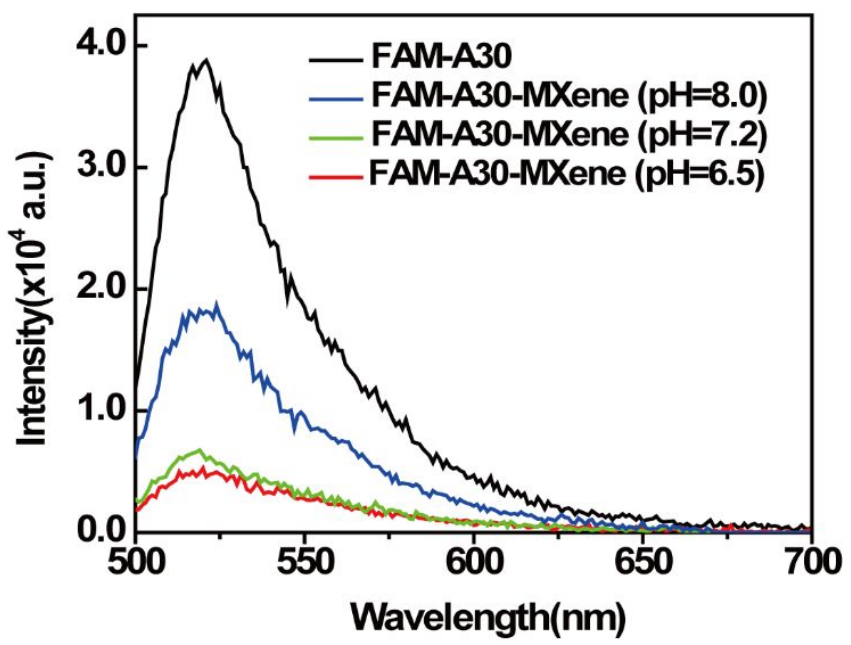

Figure S8. Fluorescent spectra of $3 \mu \mathrm{M}$ FAM-A30 mixed with $200 \mu \mathrm{g} / \mathrm{mL} \mathrm{Ti}_{2} \mathrm{C}_{3}$ MXene (a) and different salt solutions ( $1 \mathrm{mM} \mathrm{MgCl}_{2}, 1 \mathrm{mM} \mathrm{MnCl}_{2}$, and $1 \mathrm{mM} \mathrm{NaCl}$ ); (b) or under different $\mathrm{pH}$ values (1mM HEPES buffer, $\mathrm{pH}=6.5,7.2$ or 8.0 ).

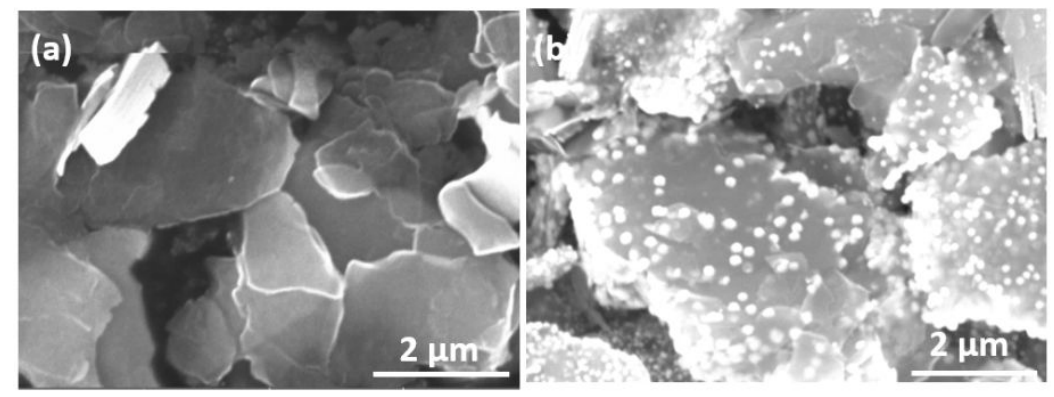

Figure S9. Scan electronic microscopy (SEM) images of MXene $\left(\mathrm{Ti}_{3} \mathrm{C}_{2} \mathrm{~T}_{\mathrm{x}}\right)$ and MXene-Au nanoflower. 
(a)

ح PolyA $_{30} \quad \mathrm{O}=\mathrm{Ti} ; \quad \bullet=\mathrm{C} ; \quad=\mathrm{T}_{\mathrm{x}}(\mathrm{O}, \mathrm{OH}, \mathrm{F})$

0

$10 \mathrm{nM}$

$1 \mu \mathrm{M}$
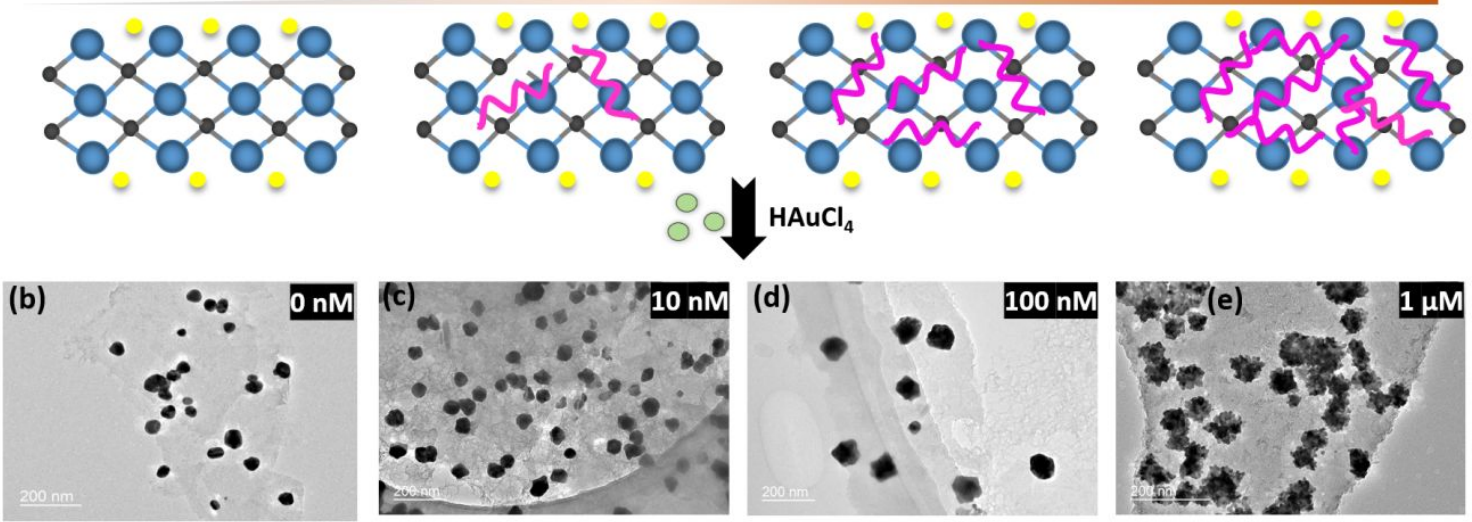

Figure S10. DNA-tailored anisotropic Au nanocrystal growth on MXene. (a) Schematic illustration.

(b-e) Representative TEM images showing dependency of the size and anisotropy of Au nanostructures on the concentration of oligonucleotide (A30) concentration from 0 to $1 \mu \mathrm{M}$.

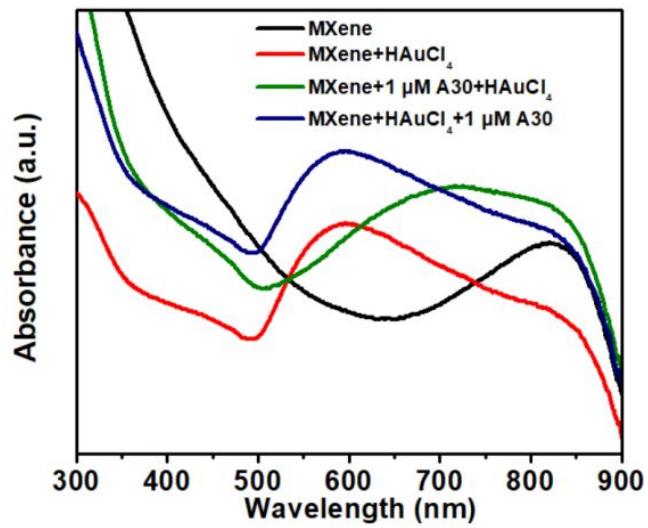

Figure S11. The UV-vis absorption of $\mathrm{MXene}$ incubated with $\mathrm{HAuCl}_{4}, \mathrm{MXene}$ incubated with $25 \mu \mathrm{L}$ $\mathrm{HAuCl}_{4}(25 \mathrm{mM})$, MXene incubated with $1 \mu \mathrm{M} \mathrm{A} 30$ oligonucleotides and $25 \mu \mathrm{L} \mathrm{HAuCl}{ }_{4}(25 \mathrm{mM})$, MXene firstly incubated with $25 \mu \mathrm{L} \mathrm{HAuCl}_{4}(25 \mathrm{mM})$, then $1 \mu \mathrm{M}$ A30 oligonucleotides. 


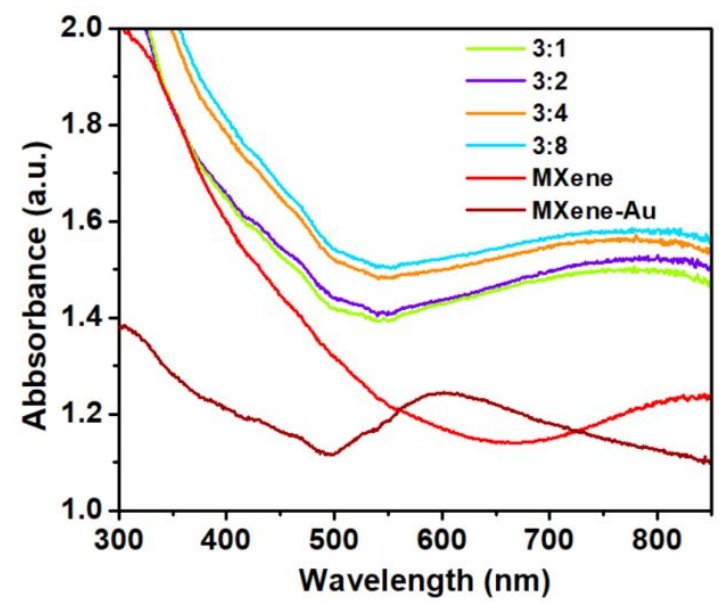

Figure S12. UV-vis absorption spectra of $\mathrm{Ti}_{3} \mathrm{C}_{2}-\mathrm{Au}$ nanoflowers prepared with multiple ratios of $\mathrm{Au} / \mathrm{Ti}$.

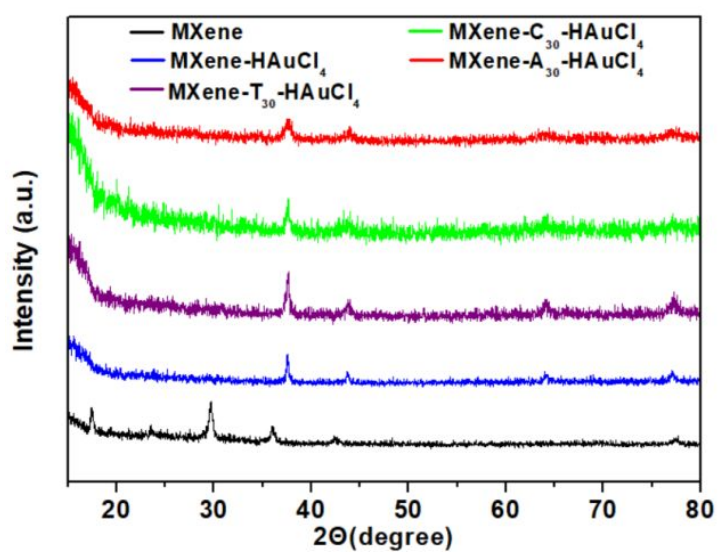

Figure S13. The powder X-ray diffraction patterns of delaminated MXene (black line), MXene-Au nanosphere (blue line), MXene-Au NF_T30 (purple line), MXene-Au_C30 (green line), MXene-Au NF_A30 (red line). 
(a)
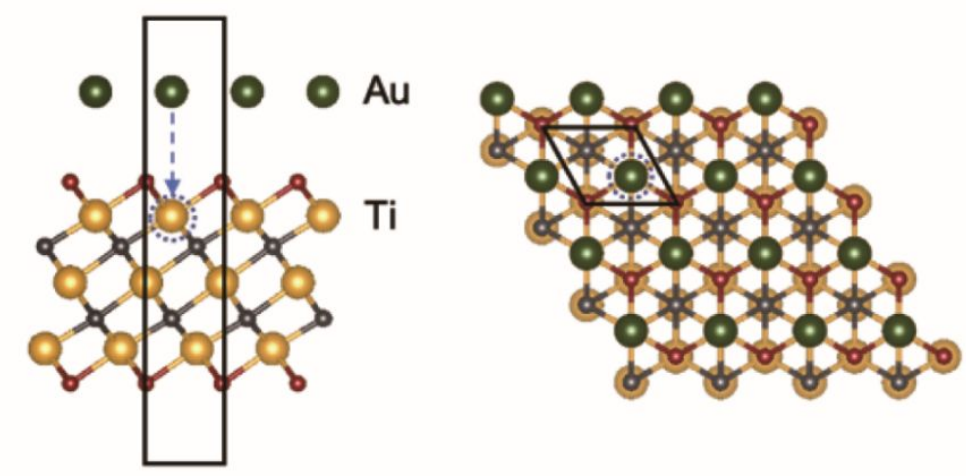

(b)
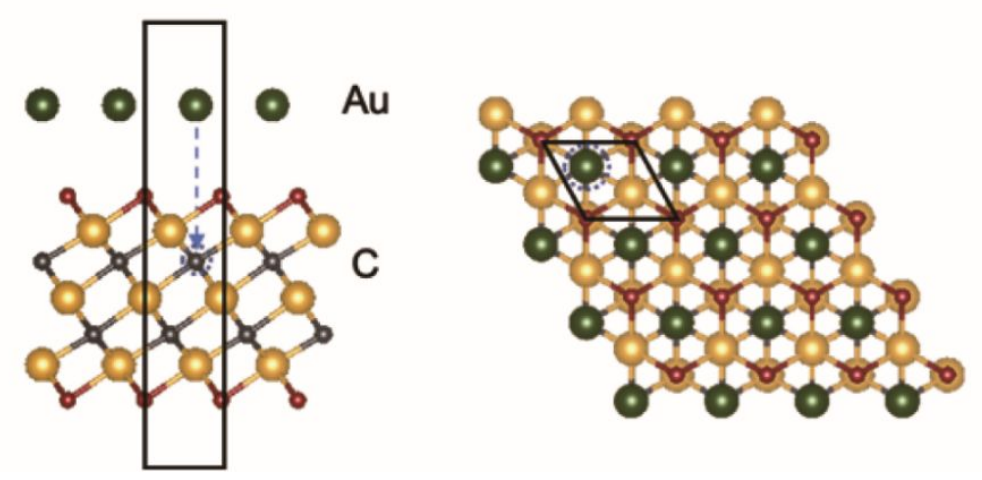

Figure S14. Two typical stacking mode of $\mathrm{Au}-\mathrm{Ti}_{3} \mathrm{C}_{2} \mathrm{~F}_{2}$. Side view and top view of (a) stacking mode A (Au locates above uppermost Ti atom) and (b) stacking mode B (Au locates above uppermost C atom). Unit cells are denoted with rectangular and parallelogram in the side view and top view, respectively. 
Table S2. Ti- $_{\mathrm{x}}\left(\mathrm{T}_{\mathrm{x}}=\mathrm{F}, \mathrm{O}, \mathrm{OH}\right)$ bond stretching after depositing metal layer.

\begin{tabular}{|l|l|l|l|}
\hline & $\mathrm{Ti}_{3} \mathrm{C}_{2} \mathrm{~F}_{2}$ & $\mathrm{Ti}_{3} \mathrm{C}_{2} \mathrm{O}_{2}$ & $\mathrm{Ti}_{3} \mathrm{C}_{2}(\mathrm{OH})_{2}$ \\
\hline $\mathrm{Au}$ & $-0.84 \%$ & $-0.12 \%$ & $-2.07 \%$ \\
\hline $\mathrm{Pd}$ & $-0.83 \%$ & $1.39 \%$ & $-2.98 \%$ \\
\hline $\mathrm{Pt}$ & $-1.48 \%$ & $-1.10 \%$ & $-3.38 \%$ \\
\hline
\end{tabular}

(a)

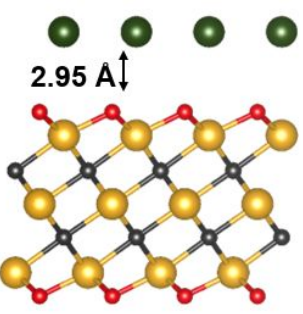

Side view

(b)

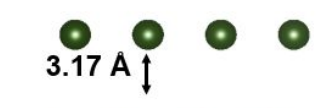

$\mathrm{Au}-\mathrm{Ti}_{3} \mathrm{C}_{2} \mathrm{~F}_{2}$

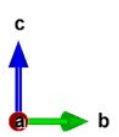

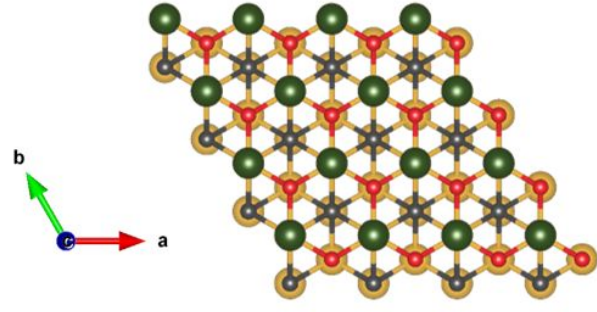

Top view

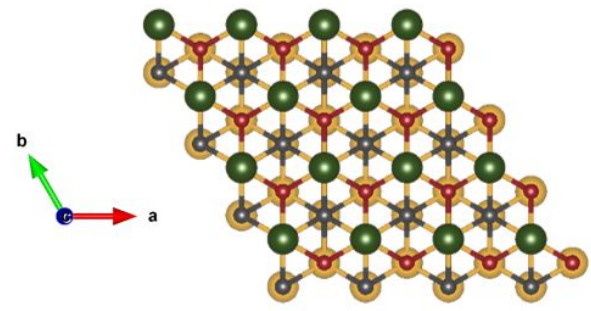

Top view

Figure S15. Side and top views of the most favorable configurations for $\mathrm{Au}$ atoms on (a) $\mathrm{Ti}_{3} \mathrm{C}_{2} \mathrm{O}_{2}$ (b)

$\mathrm{Ti}_{3} \mathrm{C}_{2} \mathrm{~F}_{2}$. The distance in the $z$-direction between the metal atoms and material surfaces are indicated in all configurations. 
Table S3. Vertical distance $(\AA)$ between metal and MXene layer.

\begin{tabular}{|l|l|l|l|}
\hline & $\mathrm{Ti}_{3} \mathrm{C}_{2} \mathrm{~F}_{2}$ & $\mathrm{Ti}_{3} \mathrm{C}_{2} \mathrm{O}_{2}$ & $\mathrm{Ti}_{3} \mathrm{C}_{2}(\mathrm{OH})_{2}$ \\
\hline $\mathrm{Au}$ & 3.170 & 2.952 & 1.867 \\
\hline $\mathrm{Pd}$ & 2.937 & 1.817 & 1.644 \\
\hline $\mathrm{Pt}$ & 2.998 & 2.375 & 1.744 \\
\hline
\end{tabular}

(a)

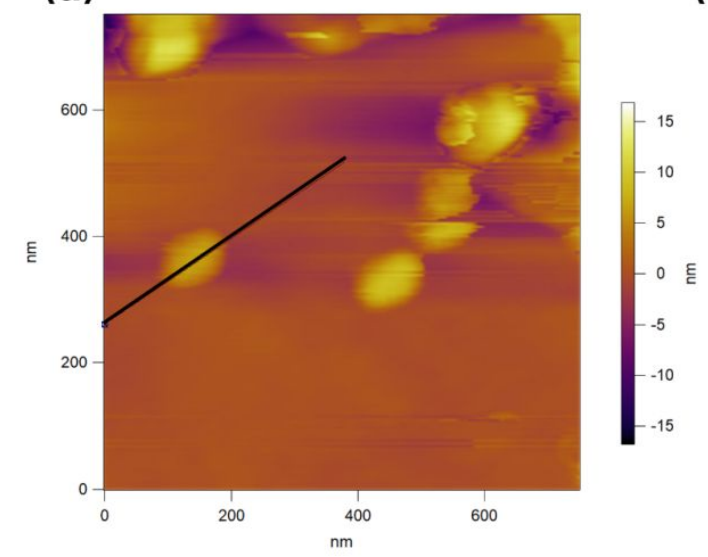

(b)

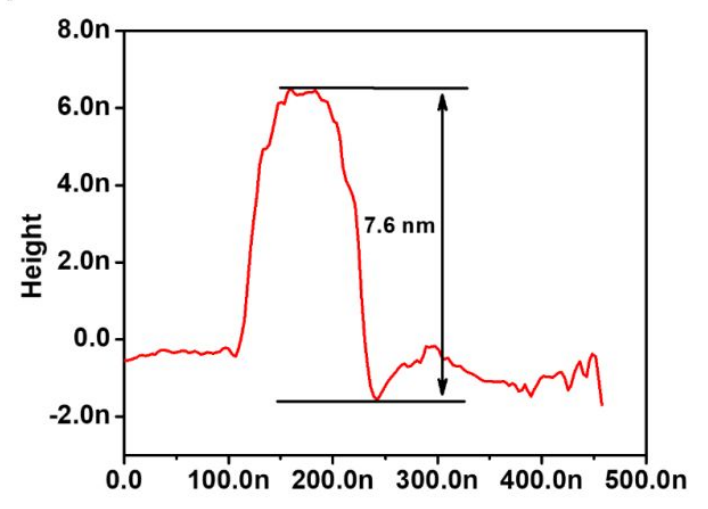

Figure S16. Representative AFM image and height profile of $\mathrm{Pd}$ nanoplates on $\mathrm{Ti}_{3} \mathrm{C}_{2} \mathrm{~T}_{\mathrm{x}}$.

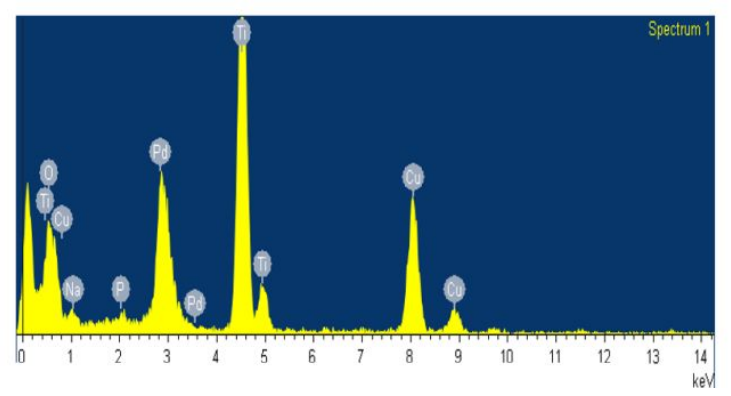

Figure S17. The EDS spectrum of MXene-Pd nanodendrites. 

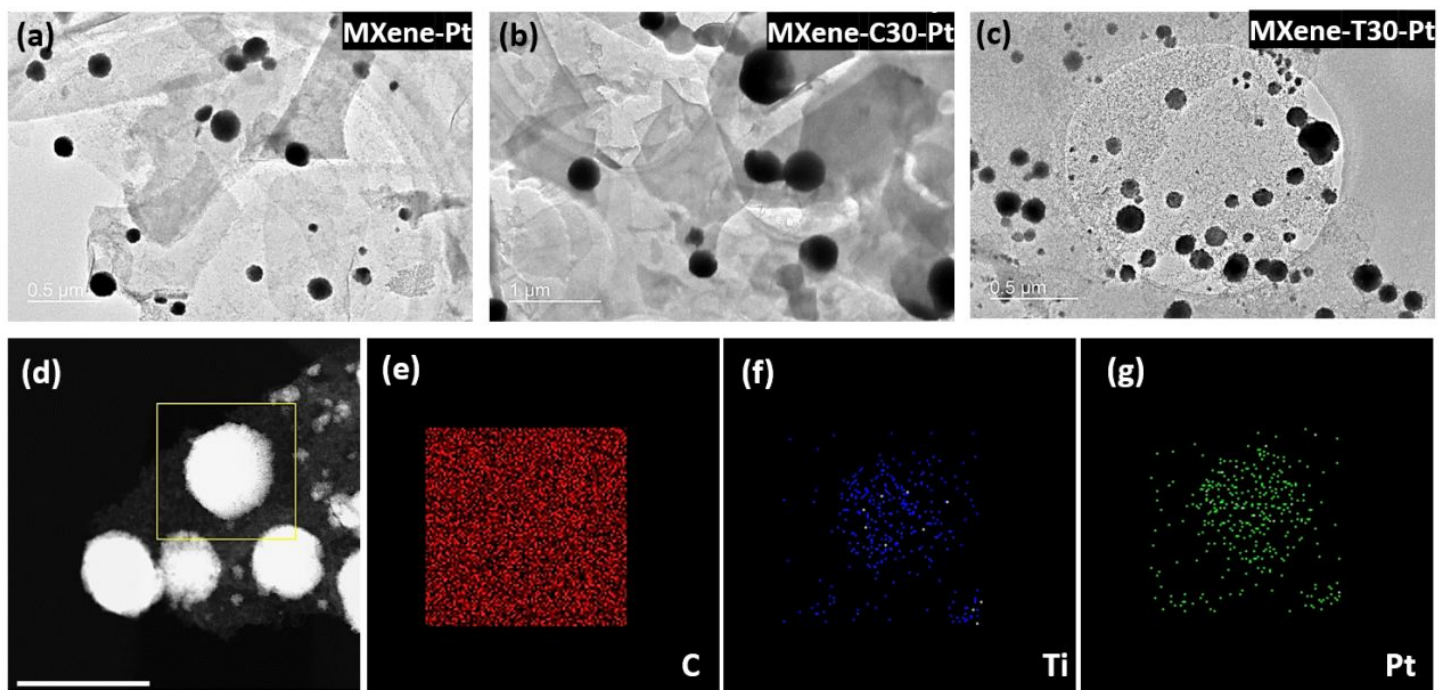

(f)

(g)

Figure S18. DNA-tailored Pt growth on MXene. Representative TEM images indicated dependency of the size and anisotropy of Au nanostructures on MXene (a) in the absence of DNA, (b) $3 \mu \mathrm{M} \mathrm{C} 30$, (d) $3 \mu \mathrm{M}$ T30. (e) HAADF-STEM of T30 mediated Pt nanosphere on MXene (e-g) EDS-STEM of the area outlined by the yellow rectangle in (e). Scale bars are $300 \mathrm{~nm}$. The images indicates that the MXene@ Pt nanocluster consists of C, Ti and Pt. The scale bar is $300 \mathrm{~nm}$.

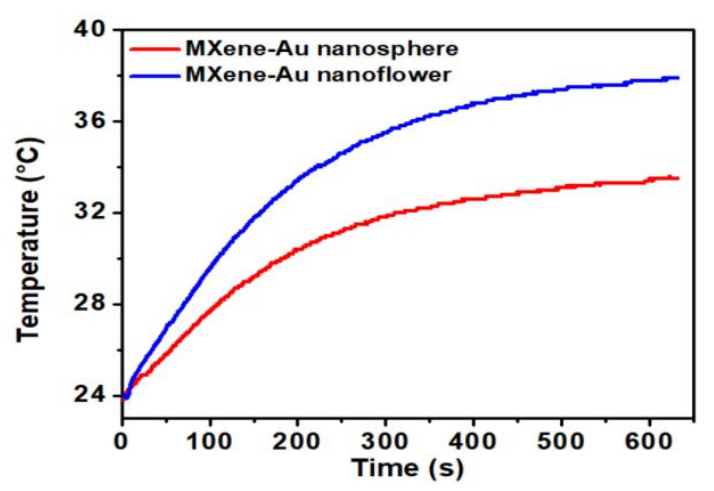

Figure S19. Photothermal heating curves of the MXene-Au nanoflower and MXene-Au nanosphere at the concentrations of $200 \mu \mathrm{g} \cdot \mathrm{mL}^{-1}$ under $808 \mathrm{~nm}$ laser irradiation at a power density of $0.263 \mathrm{~W}$ for 10 min.

Different $\mathrm{Ti}_{3} \mathrm{C}_{2}$-Au nanostructures were irradiated with $808 \mathrm{~nm}$ diode laser. As shown in Figure $\mathrm{S} 19$, the temperature was enhanced by $14{ }^{\circ} \mathrm{C}$ for $\mathrm{Ti}_{3} \mathrm{C}_{2}$-Au nanoflowers within 10 min irradiation, whereas 
the temperature change for $\mathrm{Ti}_{3} \mathrm{C}_{2}$-Au nanosphere was only $9.6{ }^{\circ} \mathrm{C}$ under the same irradiation condition, indicating the efficient photothermal conversion of the $\mathrm{Ti}_{3} \mathrm{C}_{2}$-Au nanoflower, which is attributed to the stronger absorption of $\mathrm{Ti}_{3} \mathrm{C}_{2}-\mathrm{Au}$ nanoflowers at $808 \mathrm{~nm}$.

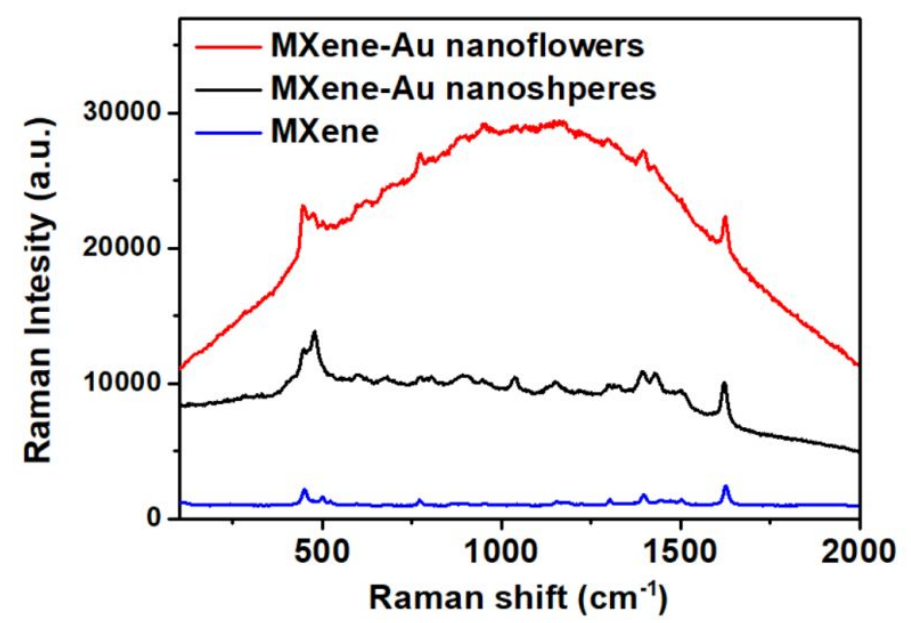

Figure S20. Raman spectra of methylene blue MB recorded from MXene, MXene-nanospheres and MXene-nanoflowers.

The SERS sensitivity of MXene-Au composites against methylene blue solution (MB) probe molecule was evaluated using a confocal Raman imaging system. MB solution $\left(1.0 \times 10^{-5} \mathrm{M}, 20 \mu \mathrm{L}\right)$ was combined with MXene, MXene-Au nanopheres, and MXene-Au nanoflowers $\left(200 \mathrm{~g} \mathrm{~mL}^{-1}, 20 \mu \mathrm{L}\right)$ and adsorbed onto the surface of nanoparticles. As shown in Figure S20, the Raman bands of MB molecule are visible, but the intensity is very low. When the same concentration of analytes is drop-casted on $\mathrm{Ti}_{3} \mathrm{C}_{2} \mathrm{~T}_{\mathrm{x}}-\mathrm{Au}$ nanospheres and $\mathrm{Ti}_{3} \mathrm{C}_{2} \mathrm{~T}_{\mathrm{x}}-\mathrm{Au}$ nanoflowers with SERS enhancement factors of $10^{4}$ and $2.4 \times 10^{4}$, respectively. The Raman bands of the MB molecule are well-resolved, and the intensity rises noticeably, indicating a good SERS effect on $\mathrm{Ti}_{3} \mathrm{C}_{2} \mathrm{~T}_{\mathrm{x}}-\mathrm{Au}$ NPs. However, due to the formation of $\mathrm{Au}$ NF hotspots from the electric field at the NF tips, Au nanoflowers exhibit higher SERS activity than Au nanospheres. 


\section{References}

1. Garrity, K. F.; Bennett, J. W.; Rabe, K. M.; Vanderbilt, D., Pseudopotentials for High-Throughput DFT Calculations. Comput. Mater. Sci. 2014, 81, 446-452.

2. Giannozzi, P.; Baroni, S.; Bonini, N.; Calandra, M.; Car, R.; Cavazzoni, C.; Ceresoli, D.; Chiarotti, G. L.; Cococcioni, M.; Dabo, I., QUANTUM ESPRESSO: A Modular and Open-Source Software Project for Quantum Simulations of Materials. J. Phys.: Condens. Matter 2009, 21 , 395502.

3. Prandini, G.; Marrazzo, A.; Castelli, I. E.; Mounet, N.; Marzari, N., Precision and Efficiency in Solid-State Pseudopotential Calculations. NPJ Comput. Mater. 2018, 4, 1-13.

4. Jain, A.; Ong, S. P.; Hautier, G.; Chen, W.; Richards, W. D.; Dacek, S.; Cholia, S.; Gunter, D.; Skinner, D.; Ceder, G., Commentary: The Materials Project: A Materials Genome Approach to Accelerating Materials Innovation. APL Mater. 2013, 1, 011002. 